\title{
Algumas Reflexões aCERCA da ClíniCa SOCIAL
}

\author{
Roberta C. Romagnoli ${ }^{\star}$
}

\section{RESUMO}

O presente artigo visa a promover algumas reflexões acerca da clínica, examinando a biopolítica e o posicionamento do profissional perante esse processo, no momento atual. Nesse sentido, fundamenta-se na noção de acontecimento, viabilizando a atualização do virtual, a partir de um raciocínio de imanência e transversalidade, utilizado por Gilles Deleuze. O território clínico é assim concebido como uma multiplicidade aberta a devires que nela irrompem. Esse enfoque aponta para a necessidade de se criar uma clínica à altura de nosso tempo, comprometida com a invenção de dispositivos que visem ao resgate das linhas processuais da subjetividade, religando clínica e vida.

Palavras-chave: Psicologia Clínica. Clínica Ampla. Biopolítica. Esquizoanálise. Clínica Social.

\section{SOME REFLECTIONS ABOUT SOCIAL CLINIC}

\begin{abstract}
This article intends to develop some discussion about clinic, analysing the biopolitic and the professional actuation in this process, in the contemporaneity. In this sense, this work is based in the concept of occurrence, that promotes the virtual's actualization and an immanent and transversal line of thoughts, used by Gilles Deleuze, was applied. Then, the clinic area is conceived by a multitude of becomings. This attitude points to the necessity of creating a clinic up to todays standards, engaged with the development of new mechanisms that allows to recover the main processual lines of subjectivity reuniting clinic and actual life.
\end{abstract}

Keywords: Clinical Psychology. Enlarged Clinic. Biopolitic. Schizoanalysis. Social Clinic.

\footnotetext{
* Psicóloga, Mestre em Psicologia Social pela UFMG, Doutora em Psicologia Clí-nica pela PUC/SP, Professora Adjunto III do Departamento de Psicologia da PUC-Minas/ Núcleo Universitário Betim. Endereço: Rua Terra Nova, 125/302 Sion, Belo Horizonte - Minas Gerais, CEP: 30 315- 470. E-mail: robertaroma@uol.com.br
} 
Trata-se de inventar novos modos de existência, segundo regras facultativas, capazes de resistir ao poder bem como se furtar ao saber, mesmo se o saber tenta penetrá-los e poder tenta apropriar-se deles. Mas os modos de existência ou possibilidades de vida não cessam de recriar, de surgir novos.

(Deleuze, 1992, p. 116)

Pensar a clínica em seus aspectos sociais, sem dúvida é tarefa complexa. Todavia, essa necessidade emerge de maneira insistente para os profissionais que atuam nessa área, seja no espaço público, seja no espaço acadêmico, e até mesmo no espaço privado. Para realizar tal tarefa, inicialmente gostaríamos de fazer referência ao caminho da indagação freudiana. Percurso que se deu a partir dos impasses da clínica, sendo que era, mediante deslocamentos imprevistos no espaço terapêutico, que, o fundador da Psicanálise, formulava os problemas cruciais para a sua construção teórica. Nesse sentido, "[...] a elaboração metapsicológica freudiana era uma tentativa de solucionar, no registro conceitual, o que se colocava como obstáculo no plano da clínica" (BIRMAN, 1995, p. 32), como nos lembra o psicanalista Joel Birman ao propor uma abertura da Psicanálise para pensar novas formas de subjetivação contemporânea, na clínica, a partir do privilégio do afeto e não da representação.

Entretanto, na problematização que pretendemos efetuar nesse texto, não nos ateremos à Psicanálise e nem tampouco a outras teorias, mas enfatizaremos a questão dos impasses, uma vez que os mesmos são essenciais para o questionamento atual de nossas práticas. Que impasses se apresentam hoje para nós, profissionais de saúde? O que precisamos enfrentar para construir uma nova clínica? Sim, porque precisamos fazer uma clínica, em construção permanente, que tenha como objetivo estar à altura do nosso tempo.

Mas como anda o nosso tempo? Com certeza, o mundo contemporâneo possui grande ênfase na formação de especialistas o que traz como conseqüência a cisão entre conhecimento e engajamento social. Tamanha ênfase tecnicista distancia-se sinistramente da responsabilidade social de qualquer prática, pois pensar somente nos aspectos técnicos desconsidera os efeitos sociais e políticos de qualquer teoria, de qualquer intervenção. Todavia, contradizendo essa leitura, afirmamos que não há clínica que não seja social. Social entendido em um sentido mais amplo. Para embasar essa premissa é necessário afastar-nos da clausura individual-familiar, que os "psi" de alguma forma se apegam, e lançarmonos em um campo social mais abrangente. Pois, como destaca o filósofo Gilles Deleuze (1992, p. 180), "[...] o inconsciente não delira sobre papai-mamãe, ele delira sobre as raças, as tribos, os continentes, a histórias e a geografia, sempre um campo social mais vasto".

Afinal, que social é esse? Examinando as relações de poder na sociedade contemporânea, (HARDT; NEGRI, 2001) afirmam-no como inerente ao espaço social. Através do que os autores chamam de biopolítica, evidencia-se a presença sutil e constante do poder, embora o discurso neoliberal apregoe o contrário, insis- 
tindo que em momento algum da humanidade, a escolha, a possibilidade de opção foi tão disseminada na humanidade. Esse poder encontra-se calcado em fazer viver, e em multiplicar as formas de existência, em controlar as condições de vida com todo o entorno que faz parte do ser e estar no mundo. Poder positivo, que penetra na vida dos homens e na força que essa vida comporta. Poder produtivo.

Decifrando a relação entre poder e saber, o filósofo Michel Foucault nos permite também refletir acerca das relações de poder que perpassam nossas inserções profissionais. Para o autor, o aparecimento dos saberes, entendidos como formações discursivas e suas respectivas práticas, ocorre em momentos históricos descontínuos, estando intimamente ligados com a questão do poder. Vale lembrar que nem o saber nem o poder são dispositivos universais e a-históricos, agindo apenas no macro, no molar. São, sim, produtos de questões emergentes em determinada época, estando imbricados com a produção de subjetividades, agindo sobretudo no micro, nos espaços sociais moleculares. Logo, todo discurso acerca da subjetividade é um discurso histórico e político, como salienta Rodrigues (2003), a partir das idéias em questão. Essas formações discursivas possuem uma função, não necessariamente punitiva, mas de monitoração e de ordenação, convocando modos de subjetivação e delimitando a realidade social 1.

A modernidade, mais especificamente o século XIX, trouxe consigo a instalação do poder sobre o homem enquanto ser vivo, poder no qual a punição e o castigo foram substituídos pela fiscalização. O biopoder, poder sobre a vida, pode ser definido como um "[...] poder que se incumbiu tanto do corpo como da vida, ou que se incumbiu, se vocês preferirem, da vida em geral, com o pólo do corpo e o pólo da população." (FOUCAULT, 1999, p. 302). Incidindo tanto sobre o indivíduo quanto sobre a espécie humana, o biopoder possui dois eixos: o poder disciplinar e a biopolítica. O poder disciplinar, que atua sobre os indivíduos e os corpos e corresponde ao poder baseado no panóptico, encontra boa parte da sua sustentação no sistema racional e científico da sociedade moderna 2. A biopolítica, por sua vez, tem como área de atuação a população e é auxiliada por mecanismos de regulamentação da natalidade, da mortalidade, das capacidades biológicas, dos efeitos do meio. A biopolítica modifica parcialmente o biopoder e o utiliza; sua tecnologia não suprime a tecnologia disciplinar.

Este foi um dos fenômenos fundamentais do século XIX: o aparecimento de uma nova tecnologia de poder que tinha como foco a vida dos homens e não se concentrava no direito de matar, ao contrário do poder soberano, que se exercia por mecanismos de apropriação, castigos e torturas. Na época moderna, o poder não é repressivo no que se refere a seu funcionamento e efeitos, não é um dispositivo que desqualifica, limita, nega e reprime; apresenta-se como positivo, no sentido de ser constitutivo, determinante, de participar ativamente da produção de modos de subjetivação, da elaboração do cotidiano das pessoas, sujeitando-as a verdades normativas que prefixam sua vida e as suas relações. Dessa ligação entre saber e poder emergem os sistemas de vigilância. Esse sistema de controle social não é praticado apenas pelo sistema judiciário e penal, mas também pela medicina, pela pedagogia, pela psicologia, pela economia enfim, por todos os campos de saber. 
As técnicas de poder incluem a organização das pessoas em espaços, o registro e a classificação das subjetividades, a exclusão de grupos de pessoas, bem como a atribuição de identidade a esses grupos e o isolamento dos indivíduos para assegurar um melhor resultado em sua fiscalização e avaliação. Nesse contexto, o poder é acionado anonimamente, sendo difícil precisar quem o exerce; tem, assim, uma produção local, circunstancial, sustentando-se através de normas. Estas são idéias construídas às quais se concede o status de verdade. Essas verdades transitam por todos os eixos do poder e em torno das quais as pessoas são estimuladas a moldar e a fabricar suas vidas, seu cotidiano:

[...] O elemento que vai circular entre o disciplinar e o regulamentador, que vai se aplicar, da mesma forma, ao corpo e à população, que permite a um só tempo controlar a ordem disciplinar do corpo e os acontecimentos aleatórios de uma multiplicidade biológica, esse elemento que circula entre um e outro é a "norma". A norma é o que pode tanto se aplicar a um corpo que se quer disciplinar quanto a uma população que se quer regulamentar. (FOUCAULT, p. 302, 1999).

Tanto o poder disciplinar, que trata da relação indivíduo-corpo, através das disciplinas e das instituições, quanto à biopolítica, que aborda a população como problema científico e político e que trata da regulamentação dos processos biológicos do homem-espécie, apóiam-se em conhecimentos sobre a realidade, em formações discursivas, em verdades normativas em estreita combinação com a ciência. Sem dúvida, as práticas culturais e discursivas conduzem à coisificação e à submissão dos indivíduos, dos corpos e das populações, com o objetivo de aprimorar a vigilância social. Práticas discursivas que se alimentam dos mecanismos de divisão e de classificação científica e penetram nas subjetividades, induzindo-as a um papel ativo em sua própria submissão, à medida que vigiam constantemente seu próprio comportamento, avaliando, o tempo todo, as suas ações, almejando sempre uma pretensa normalidade ditada pelas disciplinas científicas. Trama de saber e poder superpostos em prol da dominação e da sujeição dos corpos e da população.

Vivemos em sociedades de controle cada vez mais amparadas nas malhas da globalização. Nessas sociedades, normas pretensamente flexíveis, das quais não conhecemos as fontes de autoridade e nem as fronteiras por elas demarcadas, sucedem-se velozmente, capturando nossos sonhos e nossos ideais. Ao contrário das sociedades disciplinares, estudadas pelo filósofo Michel Foucault, em que o poder era estático e visível, pertencendo às instituições, nesse regime atual, a relação é mais intrínseca, mais qualitativa e afetiva. Nesse sentido, o poder alastra-se rizomaticamente em redes, de tal modo que é o conjunto do corpo social que é abraçado por ele, através de mecanismos de dominação cada vez mais democráticos e imanentes ao campo social. Esse poder é exercido diretamente sobre nossos corpos e sobre nossa potência de vida, e produz estados de alienação.

Estados que, paradoxalmente, não são apenas impostos a nossas subjetividades, mas são também desejados por nós, sustentando formas de vida padro- 
nizadas, áridas, esvaziadas de vitalidade. De tal maneira que é a partir desses estados que cada um ancora um sentido de vida para si mesmo. Sentido de possuir uma identidade em que se reconheça alguma figura ideal, de pertencer a determinado grupo, de aspirar segurança, de montar projetos de vida, de consumir determinadas imagens. Sentido esvaziado, em que a vida encontra-se contida em uma fôrma serializada e estereotipada. Sendo assim, o controle prescinde das instituições e cobre anonimamente o tecido social de uma maneira intensiva e extensiva, através de um movimento de rede. O poder conquista uma penetração nunca vista e também uma flexibilização inimaginável. O poder adquire ainda uma imanência, entrelaçando-se em todos os universos e espaços, reativando-se em cada um de nós.

Mas afinal, o que se produz e o que se consome nessas sociedades, tão imbricadas com o poder? Cada vez mais, maneiras de ser, de perceber, de sentir, enfim, de viver. Nesse raciocínio, o poder respira através do nosso hálito, ganha força em nossos sentimentos, se prolifera em nossos desejos, denunciando um movimento em que os mecanismos de inclusão e de exclusão são cada vez mais interiorizados por nossas subjetividades. O poder exerce-se assim no molecular, através de microfascismos, de fluxos semióticos normativizantes.

Contudo, é importante ressaltar que a biopolítica, sobretudo no pensamento de Hardt e Negri (2001), é o poder sobre a vida mas também a potência dessa vida de fazer de si um capital. No âmago desse dispositivo, existem vidas e subjetividades que podem revirar esse jogo, uma vez que esse grau de dominação só é possível se os próprios indivíduos reativam esse poder e se encarregam disso. Vale lembrar que esse poder exerce-se sobre uma potência subjetiva e quando essa é convocada pode virar um poder de resistência contra o poder sobre a vida. Há poder na vida, poder potência, na medida em que há poder sobre a vida, poder opressão.

Fica claro portanto, que tudo isso cria uma contradição: ao mesmo tempo em que esse poder unifica todos os elementos da vida social, revela nesse processo um meio em si incontrolável, o meio do acontecimento. Meio de quase-tudo, tecido do coletivo. Coletivos vários, naturalizados, socializados, ativos, inventados. Agenciados. Unir estados, juntar situações, ligar coisas, associar subjetividades, que já se foram, que estão por aí, que estão por vir. O acontecimento compõem-se em agenciamentos que por sua vez produzem alianças e passagens entre o que está estabelecido e o devir, entre bloqueios e fluxos. O acontecimento, laço dos efeitos, emerge sempre imprevisível, trazendo o novo . A idéia de acontecimento é trabalhada ao longo da obra de Gilles Deleuze e Félix Guattari de várias formas. $\mathrm{O}$ acontecimento é um convite a inventar, atualizando linhas de virtualidade, localizando-se "entre" as conexões estabelecidas e propiciando o afloramento do inédito, a expressão das singularidades. "O acontecimento não é o que acontece (acidente), ele é no que acontece o puro expresso que nos dá sinal e nos espera."(DELEUZE, 1974, p. 152). Tensão sem fim, que cria território em que ocorrem sufocamentos, bloqueios, justaposições ${ }^{3}$. 
Conectar para dominar, traz também a possibilidade de revolucionar, de promover acontecimentos. O poder em rede admite a conexão que pode derivar tanto em uma reprodução, quanto em uma invenção. Nos permite imitar, mas também criar acontecimentos que são imanentes ao social, ao encontro de uma subjetividade com outra subjetividade, aos afetamentos que o mundo que nos rodeia provoca. Acontecimentos que materializam as forças virtuais, as potências que podem se atualizar em um vir-a-ser. Ou seja, o poder potência, que se contrapõe ao poder opressão está no meio, no interstício, e não nas extremidades, como erroneamente acreditamos. Meio que, mediante associações e junções, abre uma nova dimensão autônoma e que possui vida própria; meio do acontecimento, no qual o desejo não possui falta alguma. $\mathrm{O}$ acontecimento atualiza o virtual, eclodindo por um excedente de conexões, possibilitando a emergência do novo, localizando-se não no sujeito mas "entre" essas conexões que são estabelecidas, remetendo a situações que se fazem através de nós:

O acontecimento nunca ocorre ao sujeito: ele é aquilo pelo qual o sujeito torna-se diferente do que é. Pois ser sujeito é concebido também segundo categorias identificatórias - as categorias da subjetivação. Mas o sujeito não é o indivíduo entidade que não pode se dividir ou que se repete sem diferença. É por isso que o acontecimento é sempre "préindividual". É sempre a renúncia a si e não a identificação a si que ocorre. $\mathrm{O}$ acontecimento nunca se dá a nosso «espírito» ou a nosso senso comum, mas a nosso devir outro. (RAJCHMAN, 1993, p. 189).

Nessa perspectiva, Como vimos acima, não se enfatiza o sujeito, mas o que vem antes do sujeito, e que parte de uma afirmação processual da diferença, promovendo agenciamentos, atualizando virtualidades. Segundo Lévy (1996), o virtual corresponde às forças que existem em potência e acompanham uma situação. A passagem dessas forças ao ato, dá-se pela atualização, que corresponde à produção do novo. $\mathrm{O}$ virtual não se caracteriza pela ausência de existência na realidade, como aparece no senso comum. O virtual não se opõe ao real, mas sim ao atual, que é a resposta a essa potência, a essa força em forma resolução da mesma. Contudo, o virtual nunca está presente, apenas se desprende dos acontecimentos, no instante em que se realiza. Produtoras de efeitos, as virtualidades inventam espaços e tempos.

Realizando um breve percurso histórico do uso da expressão Clinica Social, ressaltamos que esta começa a circular no Brasil na década de 80, revelando uma série de mudanças em curso. Com a abertura política irrompe, em nosso país, a força dos movimentos sociais e a ampliação do conceito de político, bem como a crítica à neutralidade da clínica. Esse novo posicionamento confronta a idéia dominante da prática clínica, até então definida como atividade liberal e privada desenvolvida junto às classes médias e altas. Centrada no indivíduo, os objetivos dessa atividade eram, sobretudo analíticos, psicoterapêuticos e/ou psicodiagnósticos, fundamentando-se em uma concepção da clínica como um sa- 
ber/fazer universalizado, associado a uma concepção de sujeito universal e a-histórico.

Por outro lado, a Clínica Social nasce como uma prática que se pretende realizar de forma ampla, implicada com a construção de novas formas de atuação, em um certo sentido, alternativas. Em seu cotidiano de trabalho, os profissionais "psi" passam a atender uma clientela oriunda das classes populares em que a dimensão social se tornou ruidosamente presente, impondo a necessidade de outra escuta e de outra intervenção. Entretanto, Ferreira Neto (2003) nos alerta que esse tipo de atividade por si só não garante uma prática política e alternativa. A ênfase no social, em sua forma dominante, também era despolitizada e, embora, destinada ao seguimento pobre da população, também era marcada, em sua maioria, por práticas assistencialistas. $\mathrm{Na}$ ânsia de fazer diferente, não raro os profissionais de saúde usavam os mesmos modelos do consultório privado.

Atualmente com as práticas emergentes em Psicologia, percebemos que a idéia de flexibilização como desenvolvimento do trabalho clínico atual é privilegiada. Esse processo aparece como resposta à multiplicidade de elementos que permeiam a atuação do psicólogo na diversidade de espaços em que este cada vez mais se insere. Contudo, é importante pontuar a necessidade de uma análise crítica mais cuidadosa, uma vez que fazer um trabalho com o social não é por si só uma prática ética e libertária. A Clínica Social como setting de acolhimento de diferentes classes sociais, em diferentes espaços de trabalho tanto no setor público como nas ONGs pode nada mais realizar do que uma adaptação dos profissionais e dos procedimentos ao mercado globalizado, distanciando-se da inventividade. Essas alterações de público e de demanda em si não garantem nenhum avanço, apenas respondem a um movimento de psicologização dos problemas da vida e aprimoram os mecanismos de exclusão do capitalismo, partindo de uma visão de um sujeito que sofre e que deve ser sujeitado a uma prática clínica que o possibilite otimizar sua eficiência, adaptando-o às exigências da vida contemporânea.

Embasando-nos nas idéias discutidas anteriormente, enfatizamos que a Clínica Social não é a clínica dos excluídos, das camadas baixas, do oprimidos, somente, e nem tampouco dos novos espaços de atuação que os psicólogos estão se inserindo. É, sobretudo, a clínica de qualquer lugar, de qualquer público, que insiste em combater essa massificação cada vez mais presente e buscar conexões e acontecimentos. Isso porque as alianças nômades e o que ocorre entre elas, são as verdadeiras potências da vida. A Clínica Social é a clínica do devir-outro. Deviroutro que não corresponde a tornar-se o outro, escapando de si mesmo, mas sim sustentar a diferença desse outro, deixando-se afetar pelo ritmo, pela intensidade desse outro, estabelecendo associações, agenciamentos. Criar, inventar, conectar com o que nos tira de nós mesmos, insistir na singularidade do nosso território existencial e dos nossos clientes, é resistir.

Por outro lado, ignorar essa problemática, pode incitar ao individualismo, ao narcisismo, ao consumismo incrementados pelos próprios psicólogos. Poder de diagnosticar. Poder de rotular. Poder de conhecer mais sobre o cliente do que 
ele mesmo. Condenar. Por esse viés, o terapeuta situa-se hierarquicamente ao cliente, por ser especialista e estar lá para ensinar ao cliente o que ele tolamente não sabe. Fundamentado em seus estudos, que podem induzir a uma coreografia ensaiada e sem vida, o terapeuta molda subjetividades sem questionar-se, em um exercício de superioridade inabalável. Nem lhe passa pela cabeça que pode estar a incrementar um estado de alienação que separa a vida da invenção. Submetendo o cliente ao seu modelo, o profissional repete, desvitaliza, reproduz. Reduz a um padrão de compreensão esse infinito de impressões, sensações, de forças denunciado um vício de enquadre; moldura contra o que não tem nome, o que não se sabe, o imprevisível.

E como a resistência e o acontecimento introduzem-se no espaço terapêutico? Fico pensando que no encontro terapêutico não basta conhecer aparatos conceituais e técnicos eficientes, ou mesmo ter boa vontade para ajudar. É necessário ir à razão que nos fez terapeuta. Razão que escapa à formação adquirida, às teorias utilizadas, ao lugar do estabelecido e que corresponde, de fato, ao desconhecido, ao contato com a diferença vibrando em instantes de desamparo, desespero, diversão, tesão. Atividade de livrar-se do sujeito psicológico que somos e nos entregar ao acaso, em um agenciamento que nos leva a lugares inimagináveis e imprevistos, a outros territórios existenciais. Como Marcel Proust que defende uma ultrapassagem da estrutura psicológica para se fazer arte, é necessário essa mesma ultrapassagem para se fazer clínica. Coragem. Ou seja, ter ousadia para livrar-se da inteligência, que persegue verdades lógicas e chafurdar-se no caos, sem temer as forças estranhas que esse modo de viver e de clinicar provocam (DELEUZE, 1987).

E, além disso, estar atento para saber discernir essas forças e lançar-se. As forças que nos paralisam e paralisam nossos clientes, as que nos potencializam e potencializam nossos clientes, as que nos entediam, as que nos alegram, em meio a tantas outras que nos afetam. É no exercício dessa seleção que podemos criar uma resistência quanto à dominação das formas fanáticas e reducionistas da clínica, deixando existir o que é de direito, convocando possibilidades. Ou seja, clinicar não passa por buscar organizações lógicas e abstratas cada vez mais complexas e coerentes para fazer valer nossas posições, mas sim por sustentar a diferença, que sempre nos traz a alteridade e, conseqüentemente o social, usando exatamente nosso conhecimento como suporte. Suportar o constante vir a ser do encontro, devir-outro, em ato.

É importante ressaltar que o devir em ato é um sempre processo minoritário, nunca hegemônico, por isso cada um de nós deve descobrir em si sua minoria íntima, para não cultuarmos o poder sobre a vida, mas o poder da vida. Essa minoria íntima equivale àquilo que não se curva aos microfascismos que fazem parte de nossa subjetividade, àquilo que não cabe em lugar nenhum, que dá desassossego. Essa parte menor da nossa subjetividade nos permite decidir não ser um trapo existencial, mas sim ter um modo de clinicar e de viver que expresse a potência e o desejo, deixando, dessa maneira, a vida exceder-se. Refletir, criticar, analisar o que estamos fazendo com nosso poder de terapeuta, abrir-se para os afetamentos e 
estar atentos às pequenas "almas" que nascem entre nossos encontros são alguns dos dispositivos para gerar novas formas de expressão, em nós mesmos e em nossos clientes. Resistir para inventar. Isso é o que a clínica exige hoje de nós.

1 Observamos que tanto Foucault quanto Deleuze acreditam na força da palavra na produção da subjetividade; para o primeiro, essa vai se constituindo nas práticas discursivas, enquanto, para o segundo, como devir-sujeito, como processo heterogêneo no qual a linguagem é uma das suas dimensões. Michel Foucault vê o poder como relação de forças; o corpo, nesse embate, submetido às forças mais variadas: de convicção, de convencimento, de demagogia. Acredita que, perante essas forças, é necessária uma oposição, uma resistência, como estratégia de reação à dominação. Nesse ponto há uma diferença entre os dois filósofos

\section{Notas}

1 Gilles Deleuze insiste que a criação é a única resistência digna do presente, uma vez que afirmar não é negar, mas sobretudo diferenciar, insistindo na noção de força como potência. Michel Hardt e Toni Negri fazem uso do pensamento de Foucault associando-o com o pensamento de Deleuze, trabalhando a questão da biopolítica a partir do poder como potência.

2 O panóptico foi projetado por Jeremy Benthan (1748-1832), no século XVIII, e corresponde a uma estrutura arquitetônica circular composta por várias celas que se voltam para uma torre ao centro. Dessa torre pode-se ver tudo sem que as pessoas que ocupam as celas vejam quem está na torre. Esse edifício tem grande eficácia no exercício da vigilância, uma vez que incita as pessoas a atuar como se estivessem sendo observadas o tempo todo.

3 Badiou (1995) também situa o acontecimento como uma exigência de um novo posicionamento, como ruptura que exige uma outra composição, como vetor de processos de subjetivação. Contudo insiste no sujeito como suporte do acontecimento, sendo que é a fidelidade ao acontecimento que nos obriga a decidir uma nova maneira de ser. Nesse sentido, é uma experiência que propicia o aparecimento do sujeito. Essa idéia opõe-se ao pensamento deleuziano do mesmo conceito, que enfatiza a processualidade, as interfaces da subjetividade com o virtual .

\section{REFERÊNCIAS}

BADIOU, A. A ética: um ensaio sobre a consciência do mal. Rio de Janeiro: Relume Dumará, 1995.

BIRMAN, J. Sujeito e estilo em psicanálise: sobre o indeterminismo da pulsão no discurso freudiano. In: MOURA, A. H. de. (Org.). As pulsões. São Paulo: Escuta/ EDUC, 1995. p. 25-51.

DELEUZE, G. A lógica do sentido. São Paulo: Perspectiva, 1974. . Conversações. Rio de Janeiro: Ed. 34, 1992. . Proust e os signos. Rio de Janeiro: Forense Universitária, 1987.

FOUCAULT, M. Aula de 17 de março de 1976. In: . Em defesa da sociedade: curso no Collège de France (1975-1976). São Paulo: Martins Fontes, 1999. p. 285-319.

HARDT, M; NEGRI, A. Império. São Paulo: Record, 2001. 
FERREIRA NETO, J. L. Qual é o social da clínica? Uma problematização. Pulsional - Revista de Psicanálise, São Paulo, v. 167, n. 1, p. 57-65, mar. 2003. LÉVY, P. O que é o virtual? São Paulo: Ed. 34, 1996.

RAJCHMAN, J. Lógica do sentido, ética do acontecimento. Cadernos de Subjetividade, São Paulo, v.1, n. 1, p. 189-193, jul. 1993.

RODRIGUES, S. M. A relação entre o corpo e o poder em Michel Foucault. Psicologia em Revista, Belo Horizonte, v. 9, n. 124, p. 109-124, jun. 2003.

Recebido em: dezembro / 2005 Aceito em: Junho/ 2006 